\title{
PENGARUH KOMUNIKASI DAN KONTEN VISUAL DALAM MEDIA SOSIAL INSTAGRAM TERHADAP KEPUTUSAN PEMBELIAN JASA FOTOGRAFI DI SWEETESCAPE JAKARTA
}

\author{
[Effect Of Visual Communication And Content In Social Media Services \\ Instagram Buying Decisions SweetEscape Photography In Jakarta] \\ Maria Elisabeth Olivia Putri Anggoro" ${ }^{1)}$, Lexi Pranata B. L., S.Kom., MBA., M.M., CEM 2) \\ 1)International Hospitality and Tourism Business, Universitas Ciputra Surabaya \\ 2)International Hospitality and Tourism Business, Universitas Ciputra Surabaya
}

Diterima 30 September 2020 / Disetujui 27 November 2020

\begin{abstract}
SweetEscape is a holiday photography service company from Jakarta, Indonesia. This study aims to determine the effect of communication with visual content on social media Instagram on purchasing decisions for SweetEscape photography services. This research uses quantitative methods. The data collection technique was carried out by distributing online questionnaires to followers of the Instagram SweetEscape Jakarta account with an assessment using the Likert scale. The population in this study were followers of the Instagram @ sweet.escape account, with a total sample of 100 respondents who were taken using the purposive sampling method - Probability Sampling. According to the results of data analysis, it can be concluded that communication and visual content were found to have a positive and significant effect on customer purchasing decisions at SweetEscape.
\end{abstract}

Keywords: Communication, Visual Content, Buying Decisions

\begin{abstract}
ABSTRAK
SweetEscape merupakan perusahaan jasa fotografi liburan yang berasal dari Jakarta Indonesia. Dalam penelitian ini bertujuan untuk mengetahui pengaruh komunikasi dengan konten visual dalam media sosial instagram terhadap keputusan pembelian jasa fotografi SweetEscape. Penelitian ini menggunakan metode kuantitatif. Teknik pengumpumpulan data dilakukan dengan cara menyebarkan kuesioner online kepada pengikut dari akun instagram SweetEscape Jakarta dengan penilaian menggunakan skala likert. Populasi dalam penelitian ini adalah pengikut dari akun instagram @sweet.escape, dengan jumlah sampel sebanyak 100 responden yang diambil menggunakan metode Purposive Sampling - Probability Sampling. Menurut hasil analisis data, dapat disimpulkan bahwa komunikasi dan konten visual ditemukan berpengaruh positif dan signifikan terhadap keputusan pembelian customer di SweetEscape.
\end{abstract}

Kata Kunci: Komunikasi, Konten Visual, Keputusan Pembelian.

\section{PENDAHULUAN}

Internet telah menjadi kebutuhan manusia sejak tahun 1969, terkhusus di zaman modern saat ini yang telah berkembang dengan adanya fitur-fitur baru hingga munculnya media sosial pada tahun 1978.

*Korespondensi Penulis:

E-mail:

llimbing@ciputra.ac.id ${ }^{(2)}$
Dalam buku Chris Brogan (2010:11) dengan judul Social Media 101 Tactic and Tips to Develop Your Business Online mendefinisikan bahwa media sosial yaitu "Social media is a new set of communication and collaboration tools that enable many types of interactions that were previously not available to the common person". Media sosial ditawarkan dalam berbagai macam aplikasi, salah satunya adalah Instagram. 
Instagram menurut Atmoko (2012:28) merupakan sebuah aplikasi berbagi foto dengan cara upload dan juga mengambil suatu gambar atau foto dengan menerapkan filter digital yang sudah ada pada instagram tersebut untuk mengubah tampilan efek foto. Selain itu juga, membagikannya ke akun instagram milik diri sendiri.

Jokom (2018) menjelaskan bahwa komunikasi dalam media sosial instagram dapat diartikan sebagai kegiatan komunikasi perusahaan untuk menginformasikan, mempengaruhi dan mengingatkan konsumen mengenai produk yang dijual. Lee dan Benbasat (2004) mengatakan bahwa kategori komunikasi yang baik apabila dapat ditanggapi dengan cepat dan jelas. Komunikasi sendiri menurut Fauziah \& Trenggana (2016) diartikan sebagai cara atau tindakan untuk menyampaikan, membagikan, mendengarkan, merespon, dan mengembangkan pesan.

Pusparini (2015) menjelaskan bahwa konten visual berbicara tentang bagaimana membentuk sebuah pesan yang baik bagi khalayak untuk menarik perhatian, memberikan informasi, dan pesan promosi. Menurut Fauziah \& Trenggana (2016) mengatakan bahwa dalam pembentukan sebuah konten yang ideal, dapat berfokus pada grafik, warna, dan perancangan fitur yang menarik. Menurut Wallschlaeger dan Sayder (1992) dalam bukunya yang berjudul "Basic Visual Concepts and Principles" mengatakan bahwa gambar (visual) merupakan salah satu bentuk komunikasi, dan gambar (visual) dapat mengekspresikan ide dalam berbagai bentuk serta gambar juga memiliki arti penting dalam komunikasi seperti halnya lisan dan tulisan. Sedangkan menurut Gahran (2015) mengatakan bahwa konten adalah sesuatu yang disampaikan, dapat melalui teks, gambar, foto, musik dan lainnya. Konten ini merupakan istilah untuk menggambarkan dan menjelaskan kepada publik tentang sebuah informasi.

Namun, berdasarkan hasil dari observasi awal peneliti melalui wawancara langsung bahwa ternyata tidak semua orang atau para pengguna akun instagram ini ketika melihat postingan dari akun instagram
SweetEscape akan melakukan sharing, respon, repost dan listening.

Hal tersebut merupakan salah satu bentuk dari komunikasi yang mampu mempengaruhi keputusan pembelian. Menurut Kotler (2012) mengatakan bahwa keputusan pembelian berada di tahap konsumen melakukan evaluasi dari beberapa referensi yang ada di dalam pemikirannya yang menjadi suatu pilihan, pilihan ini bisa menjadi niat dalam membeli maupun tidak. Sedangkan menurut Olaepo et al (2015) menyatakan bahwa keputusan konsumen untuk melakukan suatu transaksi pada keputusan ini dibuat setelah mereka menetapkan pemikiran/keputusan terhadap suatu produk yang signifikan.

Berdasarkan uraian yang dibuat oleh peneliti, maka penelitian ini memiliki tujuan untuk mengetahui "Pengaruh Komunikasi dan Konten Visual dalam Media Sosial Instagram terhadap Keputusan Pembelian Jasa Fotografi di SweetEscape Jakarta." Hipotesis pada penelitian ini adalah diduga adanya pengaruh antara komunikasi dengan keputusan pembelian dan diduga adanya pengaruh antara konten visual terhadap keputusan pembelian. Hasil dari penelitian ini diharapkan dapat digunakan sebagai sebuah masukan kepada perusahaan SweetEscape atau saran untuk menjadi salah satu sumber data bagi perusahaan SweetEscape. diharapkan dapat bermanfaat sebagai referensi dalam sebuah karya ilmiah kepada para pembaca, baik di lingkungan kampus Ciputra atau diluar kampus Ciputra. Dan juga dapat bermanfaat sebagai masukan yang dapat dikembangkan untuk penelitian yang akan dibuat selanjutnya.

\section{METODE PENELITIAN}

Penelitian ini menggunakan rancangan penelitian metode kuantitatif. Sugiyono (2017:8) menjelaskan tentang pengertian kuantitatif yaitu dimana metode penelitian seperti ini digunakan untuk meneliti populasi atau sampel tertentu dengan berlandaskan filsafat positivisme. Penelitian kuantitatif ini bersifat statistik. Dan dalam 
penelitian kuantitatif ini dilakukan cara dengan menguji hipotesis yang ditetapkan. Pengumpulan data dalam penelitian kuantitatif ini dilakukan dengan membagikan kuesioner online kepada responden dengan jumlah yang sudah ditentukan menggunakan rumus Yamane yaitu sebanyak 100 repsonden. Teknik sampel dalam penelitian ini adalah teknik Purposive Sampling Probability Sampling. Sugiyono (2017) mengatakan bahwa teknik purposive sampling merupakan teknik dalam menentukan suatu sampel dengan beberapa pertimbangan tertentu, dimana populasinya ditentukan dari followers instagram SweetEscape yang mengikuti akun SweetEscape dan sudah pernah menggunakan jasa fotografi SweetEscape.

Sumber dan jenis data dalam penelitian ini dibagi menjadi dua, yang pertama adalah data primer dimana untuk mendapatkan data primer peneliti akan menggunakan kuesioner secara online dengan skala likert dan akan diberikan kepada sampel yang sudah ditentukan sebelumnya yang kemudian disusun berdasarkan indikator (lihat tabel 1).

Pengumpulan data sekunder dilakukan dengan cara mengumpulkan data yang diperoleh dari jurnal-jurnal, buku-buku dan beberapa penelitian terdahulu. Selain itu juga dengan menggunakan beberapa literatur lain dimana dapat menjadi referensi dalam penelitian ini.

Setelah semua instrumen terisi dan data yang dibutuhkan terkumpul, peneliti melakukan beberapa uji yang antara lain, uji validitas, uji reliabilitas, analisis regresi linier berganda, uji hipotesis $\mathrm{T}$, uji hipotesis $\mathrm{F}$, uji koefisien korelasi R dan determinasi (R2), uji asumsi klasik yang diantaranya terdapat uji normalitas, uji heteroskedastisitas, uji multikolinearitas, uji autokorelasi dan uji linearitas.

Tabel 1. Variabel, Indikator dan Alat Ukur

\begin{tabular}{ccc} 
Variabel & Sub Variabel & \multicolumn{1}{c}{ Indikator } \\
\hline $\begin{array}{c}\text { Variabel Bebas } \\
\text { (Independen) }\end{array}$ & Komunikasi & Menangapi \\
& setiap followers \\
\hline
\end{tabular}

\begin{tabular}{|c|c|c|}
\hline & & $\begin{array}{l}\text { pertanyaan } \\
\text { followers } \\
\text { dengan cepat } \\
\text { Tanggapan } \\
\text { jelas dan } \\
\text { mudah } \\
\text { dipahami } \\
\begin{array}{l}\text { Menggunakan } \\
\text { bahasa yang } \\
\text { ramah }\end{array} \\
\end{array}$ \\
\hline $\begin{array}{l}\text { Variabel Bebas } \\
\text { (Independen) }\end{array}$ & $\begin{array}{l}\text { Konten } \\
\text { Visual }\end{array}$ & $\begin{array}{l}\text { Isi Gambar } \\
\text { Bahasa yang } \\
\text { Jelas } \\
\begin{array}{l}\text { Informasi yang } \\
\text { sesuai }\end{array}\end{array}$ \\
\hline $\begin{array}{c}\text { Variabel } \\
\text { Terikat } \\
\text { (Dependen) }\end{array}$ & $\begin{array}{l}\text { Keputusan } \\
\text { Pembelian }\end{array}$ & $\begin{array}{l}\text { Kemantapan } \\
\text { pada sebuah } \\
\text { produk } \\
\text { Merekomenda- } \\
\text { sikan kepada } \\
\text { orang lain }\end{array}$ \\
\hline & & $\begin{array}{l}\text { Pembelian } \\
\text { ulang }\end{array}$ \\
\hline
\end{tabular}

\section{HASIL DAN PEMBAHASAN}

\section{Hasil}

Berdasarkan total 100 subjek yang telah mengisi kuesioner, gambaran deskriptif dari setiap variabel akan dikelompokan menjadi 3 kriteria, Rendah, Sedang dan Tinggi dengan menggunakan rumus di bawah:

Range $=\frac{\text { Pengukuran Tertinggi }- \text { Pengukuran Terendah }}{\text { Jumlah Kategori }}$

Range $=\frac{5-1}{3}=1,33$

Berdasarkan rumus diatas, maka diperoleh kriteria dari setiap variabel yang tertera pada tabel 2 sebagai berikut:

Tabel 2. Rumus Kategorisasi

\begin{tabular}{ccc}
\hline No & Range & Keterangan \\
\hline 1 & $1,00 \mathrm{~s} / \mathrm{d} 2,33$ & Rendah \\
\hline 2 & $2,34 \mathrm{~s} / \mathrm{d} \mathrm{3,67}$ & Sedang \\
\hline
\end{tabular}




\section{$3 \quad 3,67 \mathrm{~s} / \mathrm{d} 5,00 \quad$ Tinggi}

Variabel Komunikasi diukur dengan menggunakan empat buah indikator. Total nilai untuk rata-rata variabel komunikasi yaitu sebesar 3,6975 hal ini membuktikan bahwa jawaban dari responden terhadap variabel komunikasi adalah "Tinggi". Untuk jawaban responden dengan Variabel Konten Visual yang diukur dengan menggunakan tiga indikator, total nilai rata-rata pada Variabel Konten Visual sebesar 3,6901. Dengan demikian maka dapat membuktikan bahwa jawaban dari responden terhadap konten visual adalah "Tinggi". Dan untuk Variabel Keputusan Pembelian, diukur dengan menggunakan tiga indikator dimana total nilai rata-rata sebesar 3,6803 yaitu pada variabel keputusan pembelian. Hal ini dapat membuktikan jawaban dari responden terhadap keputusan pembelian adalah "Tinggi".

\section{Pembahasan}

Berdasarkan dari hasil analisis dan pembahasan yang sudah dijelaskan diatas, penelitian ini menemukan bahwa komunikasi ditemukan berpengaruh positif dan signifikan terhadap keputusan pembelian customer di SweetEscape. Hal ini berarti dengan meningkatkan komunikasi maka keputusan pembelian pada customer di SweetEscape akan mengalami peningkatan secara signifikan. Penelitian ini juga menemukan bahwa konten visual ditemukan berpengaruh positif dan signifikan terhadap keputusan pembelian customer di SweetEscape. Hal ini berarti dengan meningkatkan konten visual maka keputusan pembelian customer di SweetEscape akan mengalami peningkatan secara signifikan.

\section{SIMPULAN}

Berdasarkan dari hasil analisis dan pembahasan yang sudah dijelaskan diatas, penelitian ini menemukan bahwa komunikasi ditemukan berpengaruh positif dan signifikan terhadap keputusan pembelian customer di SweetEscape. Penelitian ini juga menemukan bahwa konten visual ditemukan berpengaruh positif dan signifikan terhadap keputusan pembelian customer di SweetEscape.

\section{DAFTAR PUSTAKA}

Atmoko, Bambang Dwi. (2012). Instagram Handbook. Jakarta: Media Kita.

Brogan, Chris. (2010). Social Media 101: Tactics and Tips to Develop Your Business Online. John Wiley \& Sons.

Jokom, Regina. (2018). Persepsi Followersterhadap Pemasaran Restoran melalui Instagram di Surabaya. Volume 11, Nomor 1, Oktober 2018, 20-32.

Lee, Y.E., \& Benbasat, I. (2004). A framework for the study of customer interface design for mobile commerce. International Journal of Electronic Commerce, 8(3), 79-102

Fauziah, A., \& Trenggana, A. F. (2016). Pengaruh penggunaan social media terhadap tingkatan brand awareness HijUp.com di kota Bandung. https://openlibrary.telkomuniversity.a c.i/home/catalog/id/116385/slug/pen garuh-penggunaan-social-mediaterhadap-tingkatan-brandawareness.html (Diakses pada 18 April 2019).

Wallschlaeger, Charles \& Sayder, Cynthia. (1992). Basic Visual Concept and Principles. New York: McGraw-Hill Higher Education.

Kotler, Philip dan Kevin Lane Keller. (2007). Manajemen Pemasaran. Edisi Kedua Belas, Jilid 1, dialihbahasakan oleh Benjamin Molan. Jakarta: PT Indeks. 